\title{
Analysis of PrimaryT Cell Responses to Intact and Fractionated Microbial Pathogens
}

\author{
K.Pfeffer', B.Schoel ${ }^{3}$, H.Gulle ${ }^{3}$, Heidrun Moll ${ }^{2}$, Sandra Kromer', S.H.E. Kaufmann', \\ and H.WAGNER ${ }^{1}$ \\ 1 Institute of Medical Microbiology and Hygiene, Technical University of Munich, FRG \\ 2 Institute of Clinical Microbiology, University of Erlangen, FRG \\ 3 Institute of Medical Microbiology, University of UIm, FRG
}

\section{SUMMARY}

Freshly isolated human $T$ lymphocytes were tested for their response to mycobacteria, mycobacterial lysates, 2 dimensional (2D) PAGE separated mycobacterial lysates, leishmania and defined leishmanial antigen preparations. While $\gamma \delta \mathrm{T}$ cells proliferated vigourously in the presence of mycobacteria and mycobacteria derived lysates, a significant stimulation from $2 \mathrm{D}$ gel separated lysates was not detected. In addition $\gamma \delta \mathrm{T}$ cells failed to respond towards leishmania or leishmanial components. In the $\alpha \beta \mathrm{T}$ cell compartment some donors, presumably according to their state of immunity against mycobacteria, responded to mycobacteria, mycobacterial lysates and $2 \mathrm{D}$ gel separated mycobacterial lysates. Neither freshly isolated $\gamma \delta \mathrm{T}$ cells nor $\alpha \beta$ T cells from naive donors did mount a significant immune response against leishmania.

\section{INTRODUCTION}

Within the last few years studies revealed the existence of two distinct $T$ lymphocyte subsets, characterized by expression of either an $\alpha \beta$ T cell receptor- (TCR) or a $\gamma \delta$ TCR heterodimer(Brenner et al. 1988; Davis and Bjorkman, 1988; Raulet, 1989; Strominger, 1989). In contrast to $\alpha \beta \mathrm{T}$ cells, the biological role and the antigen specificity of $\gamma \delta \mathrm{T}$ cells has not yet been elucidated(Brenner et al. 1988; Strominger, 1989; Bluestone and Matis, 1989). Recent observations, however, have suggested an involvement of $\gamma \delta \mathrm{T}$ cells in mycobacterial infections (Janis et al. 1989; Modlin et al. 1989; Holoshitz et al. 1989; O'Brien et al. 1989; Augustin et al. 1989; Kabelitz et al. 1990). In particular, it has been shown that $\gamma \delta$ TCR expressing hybridomas derived from murine fetal thymuses recognize a $65 \mathrm{kDa}$ heat shock protein (hsp65) (O'Brien et al. 1989). In addition human $\gamma \delta \mathrm{T}$ cell lines or clones have been isolated responding to hsp65 (Holoshitz et al. 1989; Haregewoin et al. 1989).

This study was performed to characterize the responsiveness of freshly isolated human $\alpha \beta$ and $\gamma_{\delta} \mathrm{T}$ cells to molecular components derived from mycobacteria, mycobacterial lysates and 2dimensional PAGE separated lysates. We found that $\gamma \delta \mathrm{T}$ cells proliferate vigourously in response to mycobacterial lysates but not to the same lysates separated by $2 \mathrm{D}$ gel electrophoresis. In contrast $\alpha \beta$ T cells respond both to unseparated and $2 \mathrm{D}$ gel separated lysates. These data indicate that ligands recognized by $\gamma \delta$ and $\alpha \beta \mathrm{T}$ cells are biochemically different. Further analysis revealed that the major proportion of $\alpha \beta \mathrm{T}$ cells responded to components of 30-100 kDa MW, whereas the majority of $\gamma \delta \mathrm{T}$ cells was stimulated by rather small molecular weight components of $1-3 \mathrm{kDa}$. We also analysed the responses of freshly isolated $\alpha \beta$ and $\gamma \delta T$ cells to another microbial pathogen, leishmania major. However, no stimulation of $\mathrm{T}$ cells, derived from healthy donors, was observed.

\section{MATERIALS AND METHODS}

$\alpha \beta$ and $\gamma \delta \mathrm{T}$ cells were isolated from mononuclear cells (MNC) of healthy donors as described (Pfeffer et al. 1990). Briefly, adherent cells were removed from MNC by plastic adherence. E-rosetting cells were purified from nonadherent cells by E-rosette formation. For purification of $\alpha \beta$ T cells TCR 1 (T Cell Sciences) positive and CD16 (Leu11, Becton Dickinson) positive cells were removed by fluorescence activated cell sorting (EPICS V, Coulter). For isolation of $\gamma \delta$ T cells, $\alpha \beta$ T cells were depleted on a MACS-system (Stefan Miltenyi, Biotechnische 
Geräte,Bergisch Gladbach, FRG)) using BMA031 (kind gift of Dr. R. Kurrle, Behringwerke). Final purification of $\gamma \delta \mathrm{T}$ cells was achieved by removing CD16 positive cells by FACS sorting.

Lysis of mycobacteria (H37Rv), 2 dimensional PAGE separation, and electroblotling into 480 individual samples was done as described (Gulle et al. 1990), and gel filtration was performed accordingly to (Pfeffer et al. 1990). rhsp65 from E.coli clone M1103 (Thole et al. 1987) was purified as published (Kaufmann et al. 1987). Leishmania major and leishmanial antigens were prepared as published (Moll et al. 1989).

Replicate cultures of 5000 responder cells were incubated in the presence of $50,000 \gamma$-irradiated autologous feeder cells in complete RPMI1640 (20mM glutamine, 10mM Hepes, antibiotics and $10 \%$ heat inactivated human serum) and antigenic preparations as indicated. rIL-2 $(10 \mathrm{U} / \mathrm{ml}$, Eurocetus) was added unless other mentioned on day 5. Proliferation was measured by ${ }^{3} \mathrm{H}$-thymidine uptake. Proliferative responses are shown as mean values in $\mathrm{cpm}$ of replicate cultures, standard deviations were less than $10 \%$ of mean values.

\section{RESULTS}

Proliferative responses of freshly isolated human $\alpha \beta$ and $\gamma \delta$ T cells to mycobacteria and mycobacterial lysates.

An efficient isolation procedure was established to purify peripheral $\gamma \delta T$ cells from mononuclear cells by consecutive steps of plastic adherence E-rosetting, magnet activated cell sorting and finally fluorescence activated cell sorting, yielding in $2-5 \times 10^{6} \gamma \delta$ cells out of $500 \mathrm{ml}$ peripheral blood.

The in vitro responsiveness of pan-T cells, $\alpha \beta \mathrm{T}$ cells and $\gamma \delta \mathrm{T}$ cells to graded amounts of mycobacterial lysates is detailed in Table 1.

Table 1 Responsiveness of $\mathrm{T}$ cell subsets to graded amounts of mycobacterial lysates.

\begin{tabular}{|llcccccc|}
\hline Lysate & & 0 & 0.05 & 0.1 & 0.5 & 1.0 & $5.0 \mathrm{ug} / \mathrm{ml}$ \\
\hline \multirow{2}{*}{ Exp.A } & E-rosette ${ }^{+}$cells & 800 & 48663 & 53668 & 60906 & 48221 & 66615 \\
& $\alpha \beta$ T cells & 230 & 19138 & 36603 & 33675 & 19579 & 9053 \\
& $\gamma \delta$ T cells & 55 & 9878 & 28516 & 35376 & 28954 & 25638 \\
\hline Exp.B & E-rosette ${ }^{+}$cells & 240 & 10895 & 10221 & 20250 & 8158 & 867 \\
& $\alpha \beta$ T cells & 126 & 711 & 3280 & 4861 & 708 & 696 \\
& $\gamma \delta$ T cells & 100 & 28875 & 26564 & 49607 & 42508 & 8781 \\
\hline
\end{tabular}

Mean values (cpm) of two representative experiments are shown.

Stimulations of $\alpha \beta$ T cells varied from donor to donor depending on the immune status of the donor tested ( $\mathrm{H}$. Gulle, Klaus Pfeffer, unpublished results), whereas $\gamma \delta \mathrm{T}$ cells of almost all healthy donors responded vigourously to mycobacterial lysates (data not given). As indicated in Table 1 maximal proliferative responses were obtained in the range of $0.5-1 \mathrm{ug} / \mathrm{ml}$ of bacterial lysates.

Responses of $T$ cell subsets stimulated with 2 D PAGE separated mycobacterial lysates.

To characterize the $\mathrm{T}$ cell immune response at a molecular level, mycobacterial lysates were separated by high resolution 2 dimensional PAGE electrophoresis using isoelectric focusing (IEF) in the first dimension and native PAGE electrophoresis in the second dimension. Consecutively 480 individual samples were obtained from 2D gels by electroelution, and afterwards analysed individually for their stimulating capacity towards both $\alpha \beta$ and $\gamma \delta \mathrm{T}$ cells. Results are shown in Fig. 1. While $\alpha \beta$ T cells vigourously responded to many fractions (A), no 
significant response of $\gamma \delta \mathrm{T}$ cells could be obtained (B). Note that the very same $\gamma \delta \mathrm{T}$ cells proliferated vigourously to unseparated lysates (Table 1, Exp.A).

Fig. 1 Analysis of $2 \mathrm{D}$ gel separated mycobacterial lysates for stimulating capacity for either $\alpha \beta$ T cells (A) or $\gamma \delta$ T cells (B).
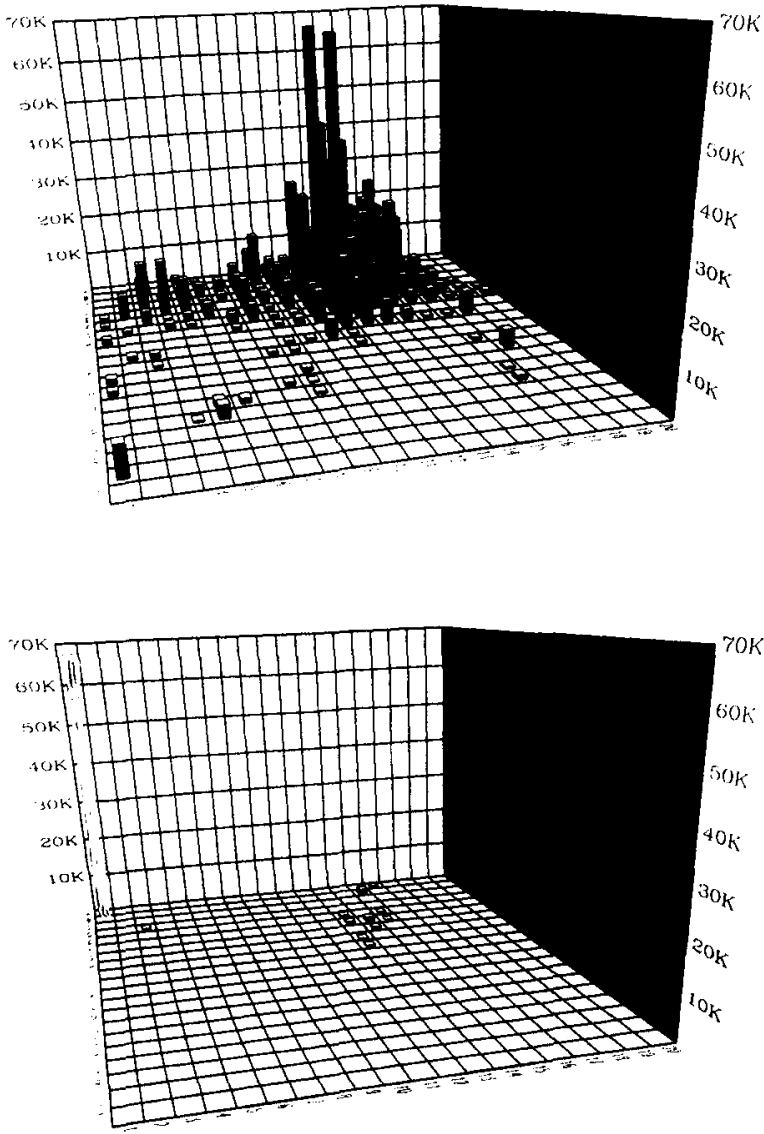

$\alpha \beta \mathrm{T}$ cells (A) or $\gamma \delta \mathrm{T}$ cells (B) (10 3 per culture), respectively, were incubated individually with 480 samples derived from electroeluted $2 \mathrm{D}$ gels. ${ }^{3} \mathrm{H}$ tyhimidine uptake was measured after 8 days. rll-2 was added at day 5 .

These results indicated that $\gamma \delta$ and $\alpha \beta T$ cells responded to distinct ligands differing at the level of their biochemical properties such as molecular weight and/or isoelectric point.

To clarify this question in detail mycobacterial lysates were separated according to size and distinct molecular weight fractions were analysed for their stimulating capacity to $\alpha \beta$ or $\gamma \delta \mathrm{T}$ cells. As shown in Fig. 2 the major stimulation of $\alpha \beta$ T cells occured in the range of $30-100$ $\mathrm{kDa}$, while responses of $\gamma \delta \mathrm{T}$ cells were mainly obtained in fractions containing mycobacterial components smaller than $10 \mathrm{kDa}$. 
Fig. 2 Response of unselected and selected $\mathrm{T}$ cell populations to size-fractionated mycobacterial lysates.

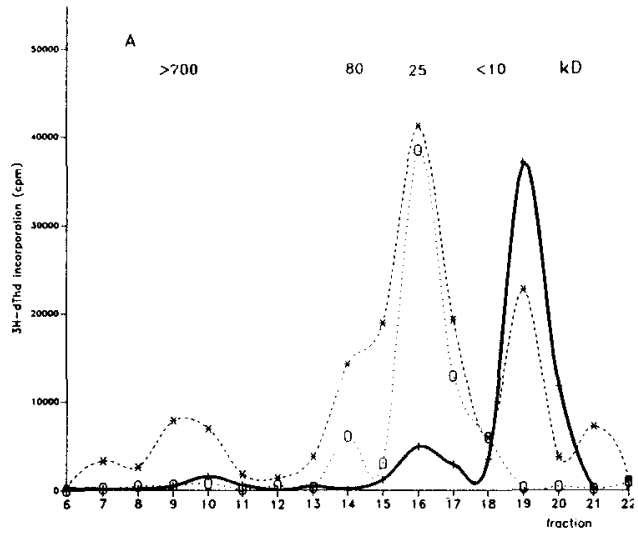

\begin{abstract}
Unselected T cells (-**--), selected $\alpha \beta$ ("००) or selected $\gamma \delta \mathrm{T}$ cells $(-+-)$ were cultered in the presence of autologous irradiated feeder cells and size- fractionated (Superose12) mycobacterial lysates. rll-2 was added on day 5 and ${ }^{3} \mathrm{H}$-Thymidine uptake was measured at day 8. Proliferative responses (y axis) are plotted against the fractions used. (Data and figure cited accordingly from Pfeffer et al. 1990).
\end{abstract}

To elucidate the role of hsp65 in primary immune responses to mycobacterial antigens freshly prepared $\gamma \delta \mathrm{T}$ cells were cocultered with intact mycobacteria, mycobacterial lysates and rhsp65 (Table 2).

Table 2 Proliferative response of $\gamma \delta \mathrm{T}$ cells against intact mycobacteria, mycobacterial lysates and rhsp65.

\begin{tabular}{|lllll|} 
Antigen & control & intact MT & MT lysate & rhsp65 \\
\hline Exp.A & 1431 & 3445 & 20430 & 1385 \\
Exp.B & 273 & 5341 & 21139 & 252 \\
\hline
\end{tabular}

Freshly isolated $\gamma \delta \mathrm{T}$ cells were cultered with antigens (MT: Mycobacterium tuberculosis) indicated (1ug/ml). $\mathrm{rll}$ 2 was added from the beginning of the culture. ${ }^{3} \mathrm{H}$-thymidine uptake was measured at day 8 . Mean values of 12 cultures are shown.

Again $\gamma \delta \mathrm{T}$ cells were stimulated by mycobacterial lysates and to a lesser degree by complete mycobacteria. But the response to rhsp65 was not significant, indicating that exogeneously added rhsp65 is poor as antigen in primary human $\gamma \delta \mathrm{T}$ cell responses.

Finally we tested whether leishmania and leishmanial antigens have the capacity to stimulate $\gamma \delta \mathrm{T}$ cells. These microbial pathogens are known to contain high levels of glycolipids and glycoproteins (Moll et al. 1989) and the possibility was considered that $\gamma \delta \mathrm{T}$ cells may preferentially respond to such antigens (Pfeffer et al. 1990). 
Table 3 Analysis of freshly isolated $\mathrm{T}$ cell populations in response to leishmania and different leishmanial derived preparations in comparison to mycobacterial lysates.

\begin{tabular}{|lccccc|}
\hline Antigen & control & leishmania & LPG & SLA & MT lysate \\
\hline E-rosette $^{+}$cells & 398 & 445 & 146 & 574 & 5381 \\
$\alpha \beta$ T cells & 680 & 788 & 202 & 438 & 862 \\
$\gamma \delta$ T cells & 3343 & 3411 & 823 & 3669 & 14201 \\
\hline
\end{tabular}

The $T$ cell populations indicated were cultered in the presence of leishania (leishmania major, $4^{*} 10^{4}$ organisms/ml), leishmanial lipoglycan (LPG, $3 \mathrm{ug} / \mathrm{ml}$ ), soluble leishmanial antigen (SLA, $1 \mathrm{ug} / \mathrm{ml}$ ) and mycobacterial lysate (MT lysate, $1 \mathrm{ug} / \mathrm{ml}$ ). Mean values from quadruplicate cultures are shown. ${ }^{3} \mathrm{H}$-thymidine uptake was determined at day 8 . rIl-2 was supplemented at the beginning of the culture.

As depicted in Table 3 neither $\mathrm{T}$ cell population proliferated in the presence of leishmania or leishmanial antigen preparations such as lipoglycan (LPG) or disrupted leishmania (SLA). On the other hand $\gamma \delta \mathrm{T}$ cells of this donor proliferated in the presence of mycobacterial lysate. These results provide evidence that leishmanial antigens are not able to evoke a significant immune reponse from unprimed human donors.

\section{DISCUSSION}

In vitro stimulation of freshly isolated human $\gamma \delta \mathrm{T}$ lymphocytes with mycobacteria involves both $\gamma \delta$ and $\alpha \beta$ T cells. Lysis of mycobacterial organisms resulted in a significant enhancement of stimulation, presumably by overcoming limitations of antigen processing in APC's. 2D gel separation of mycobacterial lysates reveals that $\alpha \beta \mathrm{T}$ cells respond to distinct and defineable mycobacterial components (Gulle et al. 1990), whereas proliferation of $\gamma \delta \mathrm{T}$ cells is virtually absent. Subsequent studies showed that the major ligands for $\gamma^{\delta} \mathrm{T}$ cells derived from mycobacterial lysates reside in a molecular weight range between 1 to $3 \mathrm{kDa}$ (Pfeffer et al. 1990), while ligands for $\alpha \beta T$ cells are contained in MW-fractions from $30-100 \mathrm{kDa}$. Electroelution of $2 \mathrm{D}$ gels is performed with an dialysis membrane with a molecular cutoff of $3.5 \mathrm{kDa}$ (Gulle et al. 1990). Therefore ligands for $\gamma \delta \mathrm{T}$ cells are not contained in 2D gel samples. We conclude from these data that ligands for $\alpha \beta$ and $\gamma \delta \mathrm{T}$ cells derived from mycobacteria differ in size and biochemical properties.

Protease digestion of mycobacterial lysates results in complete abolishment of $\alpha \beta \mathrm{T}$ cell responses, whereas $\gamma \delta \mathrm{T}$ cells show virtually unaltered responses to protease-treated lysates (Pfeffer et al. 1990). These findings could be explained by either of two conclusions: the fraction stimulating $\gamma \delta \mathrm{T}$ cells contains unusual peptides which are resistant to conventional protease digestion or, alternatively, $\gamma \delta \mathrm{T}$ cells respond themselves to non-peptides.

Observation in mice indicate that within mycobacterial lysates hsp65 represents a major immunogen for $\gamma \delta$ T cells (O'Brien et al. 1989). The results presented here indicate that in primary responses human $\gamma \delta \mathrm{T}$ cells do not respond to rhsp65. Possible explanations are that hsp65 has to be bound to cellular membranes, or that hsp65 has to be induced in the antigen presenting cells for $\gamma \delta \mathrm{T}$ cell stimulation to occur, or that the frequency of freshly isolated $\gamma \delta \mathrm{T}$ cells is rather low. Experiments evaluating these possibilities are currently performed.

Primary immune responses of $\gamma \delta \mathrm{T}$ cells to defined glycolipids of leishmania (Moll et al. 1989), as well as lysed or intact leishmania were not observed. These results are in agreement to studies indicating that in leishmania infections $\gamma \delta$ T cells do not respond (Röllinghoff et al., see this issue of CTMI). 
Acknowledgements

We thank Dr. R. Kurrle for mAb BMA031 and Dr. J.DA. Van Embden for the recombinant E.coli clone M1103 expressing hsp65.This work was supported by the SFB 322, the BMFT, and the UNDP/World Bank/WHO Special Program for Research and Training in Tropical Diseases.

\section{References}

Augustin, A., Kubo, R.T. and Sim, G.K. (1989) Resident pulmonary lymphocytes expressing the gamma/delta Tcell receptor. Nature 340:239-241

Bluestone, J.A. and Matis, L.A. (1989) TCR gamma delta cells--minor redundant T cell subset or specialized immune system component?.J Immunol 142:1785-1788

Brenner, M.B., Strominger, J.L. and Krangel, M.S. (1988) The gamma delta T cell receptor. Adv Immunol 43:133192

Davis, M.M. and Bjorkman, P.J. (1988) T-cell antigen receptor genes and T-cell recognition [published erratum appears in Nature 1988 Oct 20;335(6192):744]. Nature 334:395-402

Gulle, H., Schoel, B. and Kaufmann, S.H.E. (1990) Direct blotting with viable cells of protein mixtures separated by two-dimensional gel electrophoresis. J Immunol Methods 133:253-261

Haregewoin, A., Soman, G., Hom, R.C. and Finberg, R.W. (1989) Human gamma delta + T cells respond to mycobacterial heat-shock protein. Nature 340:309-312

Holoshitz, J., Koning, F., Coligan, J.E., De Bruyn, J. and Strober, S. (1989) Isolation of CD4- CD8- mycobacteriareactive T lymphocyte clones from rheumatoid arthritis synovial fluid. Nature 339:226-229

Janis, E.M., Kaufmann, S.H., Schwartz, R.H. and Pardoll, D.M. (1989) Activation of gamma delta T cells in the primary immune response to Mycobacterium tuberculosis. Science 244:713-716

Kabelitz, D., Bender, A., Schondelmaier, S., Schoel, B. and Kaufmann, S.H. (1990) A large fraction of human peripheral blood gamma/delta $+T$ cells is activated by Mycobacterium tuberculosis but not by its $65-\mathrm{kD}$ heat shock protein. J Exp Med 171:667-679

Kaufmann, S.H., Vath, U., Thole, J.E., van Embden, J.D. and Emmrich, F. (1987) Enumeration of T cells reactive with Mycobacterium tuberculosis organisms and specific for the recombinant mycobacterial $64-\mathrm{kDa}$ protein. Eur J Immunol 17:351-357

Modlin, R.L., Pirmez, C., Hofman, F.M., Torigian, V., Uyemura, K., Rea, T.H., Bloom, B.R. and Brenner, M.B. (1989) Lymphocytes bearing antigen-specific gamma delta T-cell receptors accumulate in human infectious disease lesions. Nature 339:544-548

Moll, H., Mitchell, G.F., McConville, M.J. and Handman, E. (1989) Evidence of T-cell recognition in mice of a purified lipophosphoglycan from Leishmania major. Infect Immun 57:3349-3356

O'Brien, R.L., Happ, M.P., Dallas, A., Palmer, E., Kubo, R. and Born, W.K. (1989) Stimulation of a major subset of lymphocytes expressing $T$ cell receptor gamma delta by an antigen derived from Mycobacterium tuberculosis. Cell 57:667-674

Pfeffer, K., Schoel, B., Gulle, H., Kaufmann, S.H. and Wagner, H. (1990) Primary responses of human T cells to mycobacteria: a frequent set of gamma/delta $\mathbf{T}$ cells are stimulated by protease-resistant ligands. Eur $\mathrm{J}$ Immunol 20:1175-1179

Raulet, D.H. (1989) The structure, function, and molecular genetics of the gamma/delta T cell receptor. Annu Rev Immunol 7:175-207

Strominger, J.L. (1989) The gamma delta T cell receptor and class Ib MHC-related proteins: enigmatic molecules of immune recognition. Cell 57:895-898

Thole, J.E., Keulen, WJ., De Bruyn, J., Kolk, A.H., Groothuis, D.G., Berwald, L.G., Tiesjema, R.H. and van Embden, J.D. (1987) Characterization, sequence determination, and immunogenicity of a 64-kilodalton protein of Mycobacterium bovis BCG expressed in escherichia coli K-12 [published erratum appears in Infect Immun 1987 Aug;55(8):1949]. Infect Immun 55:1466-1475 